\title{
Diabetes-induced eye disease among First Nations people in Ontario: a longitudinal, population-based cohort study
}

\author{
Robert J. Campbell MD MSc, Roseanne Sutherland BA, Shahriar Khan MSc, Katharine M. Doliszny PhD, \\ Philip L. Hooper MD, Morgan Slater PhD, Eliot Frymire MA, Baiju R. Shah MD PhD, \\ Jennifer D. Walker PhD, Michael E. Green MD MPH
}

See related article at www.cmajopen.ca/lookup/doi/10.9778/cmajo.20190096

Abstract

Background: In Canada, First Nations populations experience a higher incidence of diabetes and diabetes-related complications than other people. Given the paucity of information on use of preventive eye examinations and the need for interventional care for severe retinopathy among First Nations people, we carried out a population-based study to compare rates of eye examinations and interventional therapies to treat vision-threatening stages of diabetic retinopathy among First Nations people and other people with diabetes in Ontario.

Methods: In collaboration with the Chiefs of Ontario, we carried out a population-based study to identify cohorts of First Nations people and other people with diabetes in Ontario from 1995/96 to 2014/15. We used linked health administrative databases to evaluate rates of eye examination (2005/06-2014/15) and severe diabetic retinopathy treatment and compared them between the 2 populations, and between First Nations people living in and outside of First Nations communities.

Results: We identified 23013 First Nations people and 1364222 other people diagnosed with diabetes from 1995/96 to 2014/15, of whom 49.8\% (95\% confidence interval [Cl] 48.9\%-50.7\%) and 53.8\% (95\% Cl 53.7\%-54.0\%), respectively, received an eye examination in 2014/15. Eye examination rates were similar for First Nations people regardless of whether they lived in or outside a First Nations community. First Nations people developed severe diabetic retinopathy at a faster rate than other people (hazard ratio 1.19 , 95\% Cl 1.02-1.38). The gap between First Nations people and other people in the proportion requiring therapy for severe diabetic retinopathy was especially prominent among younger people. There were no significant differences in rates of diabetic retinopathy treatment in First Nations people stratified by place of residence.

Interpretation: Eye examination rates remain suboptimal among people with diabetes in Ontario and were lower among First Nations people. This is particularly concerning in light of our other findings showing an increased risk of requiring treatment for advanced diabetic retinopathy and the accelerated rate of diabetic retinopathy progression among First Nations people with diabetes.

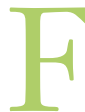
irst Nations people in Canada experience a higher incidence of diabetes and diabetes-related complications than other people. ${ }^{1-5}$ Among the many deleterious consequences of diabetes, diabetic retinopathy is the most common and is the leading cause of blindness and vision impairment in working-age adults. ${ }^{6-8}$ Diabetic retinopathy is a progressive disorder. Among the more than 3 million Canadians with diabetes, diabetic retinopathy will develop in over $60 \%$ in their lifetime. ${ }^{9-13}$ At advanced stages, diabetic retinopathy leads to severe vision loss, profoundly affecting the lives of people with diabetes. ${ }^{8,14}$

Although the risk of diabetic retinopathy is related to the degree of glycemic control, ${ }^{15,16}$ the risk of poor vision outcomes due to advanced retinopathy can be reduced through regular eye examinations and early detection. ${ }^{12,17}$ However, ensuring access to regular eye examinations for the growing population with diabetes is challenging. First Nations people may be at higher risk for not receiving screening eye examinations for several reasons, such as remoteness from care providers and comorbidity, as well as financial and cultural barriers. ${ }^{1,2}$

At advanced stages of retinopathy, interventions are required to prevent further vision loss. Although these treatments can be

\section{Competing interests: None declared.}

This article has been peer reviewed.

Correspondence to: Robert Campbell, rob.campbell@queensu.ca CMAJ Open 2020. DOI:10.9778/cmajo.20200005 
vision saving, they often indicate a failure of preventive efforts and are associated with poor vision outcomes.

Little information is available comparing the use of eye examinations and the need for interventional care for severe retinopathy among First Nations people and other people. Hence, in collaboration with the Chiefs of Ontario, we carried out a population-based study to compare rates of eye examinations and interventional therapies to treat visionthreatening stages of diabetic retinopathy among First Nations people with diabetes and other people with diabetes in Ontario.

\section{Methods}

\section{Setting and design}

We conducted a retrospective population-based cohort study in Ontario from 1995/96 to 2014/15. Details of the study methods are published elsewhere. ${ }^{18}$ Briefly, annual cohorts of all people with diabetes in Ontario were identified with the use of the Ontario Diabetes Database, a validated populationbased data set. ${ }^{19}$ In each study year, First Nations people were identified through the Indian Register, which provides information on all Registered or Status First Nations people in Canada; the remainder of the population was classified as other people in Ontario. ${ }^{18}$ The project follows REporting of studies Conducted using Observational Routinely-collected health Data (RECORD) statement guidelines. ${ }^{20}$

\section{Outcomes}

The primary outcomes evaluated were the frequency of eye examinations and the frequency of requiring treatment for advanced diabetic retinopathy. We chose these outcomes to reflect both critical prevention measures and outcomes that have major effects on vision and quality of life. ${ }^{12}$

\section{Data sources}

Data evaluated in this study were sourced from Ontario's linked population-based health administrative databases that are listed elsewhere ${ }^{18}$ and have been used in previous studies. ${ }^{21-25}$ The databases were accessed through the secure, privacy-protected environment at ICES, an independent, nonprofit research institute whose legal status allows it to collect and analyze health care and demographic data for health system evaluation and improvement. These data sets were linked by means of unique encoded identifiers and analyzed at ICES. Details regarding the data sets accessed are available in Appendix 1 of our associated methodology paper. ${ }^{18}$

To evaluate eye examination frequency, we used the Ontario Health Insurance Plan (OHIP) database, which includes information on all visits for eye examinations provided by ophthalmologists, family physicians and optometrists, as well as telemedicine care. All eye examinations for people with diabetes in Ontario are covered by OHIP.

To quantify treatments for advanced diabetic retinopathy, we used the OHIP database to identify procedures employed in the treatment of vision-threatening stages, including intravitreal medication injections (e.g., for delivery of vascular endothelial growth factor inhibitors), laser retinal photocoagulation procedures and vitrectomy surgery. Details of the codes used to identify eye examination visits and procedures are listed in Appendix 1, Supplemental Table S1 (available at www.cmajopen.ca/content/8/2/E282/suppl/DC1).

In 2004, OHIP policies regarding the coverage of routine eye examinations were changed to exclude examinations for some people aged 19-65 years. Therefore, we limited the evaluation of eye examination frequency to a 10 -year period from 2005/06 to 2014/15. The interventional outcomes evaluated in the study were not affected by changes in OHIP coverage of routine eye examinations. Hence, we evaluated outcome data over the entire study period, 1995/96-2014/15.

We used residence and postal codes to determine whether a person lived in a First Nations community. ${ }^{26} \mathrm{We}$ assigned urban or rural location using the Rurality Index for Ontario. ${ }^{27}$ The Rurality Index for Ontario measure uses inputs that are different from the data used to identify First Nations communities. The Rurality Index for Ontario score was not available for people in remote locations; hence, the residence location of those participants was defined as remote/missing.

\section{Covariates}

Covariates evaluated included age, sex, comorbidity (assessed with the Johns Hopkins Adjusted Diagnosis Groups), rurality and, for First Nations people, living in or outside of a First Nations community.

\section{Statistical analysis}

For eye examination data, we evaluated unadjusted rates to reflect adherence to a Canadian guideline for diabetic retinopathy care, which recommends regular eye examinations for people with diabetes irrespective of age or sex. ${ }^{12}$ For interventional care outcomes, we calculated age- and sex-standardized rates to adjust for differences both between and within populations over time. To compare the rates at which First Nations people and other people develop the need for interventions for advanced diabetic retinopathy, we used a Cox proportional hazards model to evaluate the time from diagnosis of diabetes to first diabetic retinopathy treatment among First Nations people and other people diagnosed with diabetes during the study period, adjusting for age and sex. Analyses were conducted with SAS Enterprise Guide version 7.1 (SAS Institute).

\section{Ethics approval}

This project received approval from the Chiefs of Ontario Data Governance Committee and the research ethics boards of Queen's University and Laurentian University.

\section{Results}

We identified 23013 First Nations people and 1364222 other people diagnosed with diabetes from 1995/96 to $2014 / 15$. The age, sex and residence rurality distributions for 2014/15 for the 2 populations are presented in Table 1. First Nations people were significantly younger than other people, with $7559(32.8 \%)$ less than age 50 years, compared 


\begin{tabular}{|c|c|c|c|c|}
\hline \multirow[b]{2}{*}{ Characteristic } & \multicolumn{4}{|c|}{ No. (\%) of people* } \\
\hline & $\begin{array}{l}\text { First Nations people } \\
\qquad n=23013\end{array}$ & $\begin{array}{l}\text { First Nations people } \\
\text { in First Nations } \\
\text { community } \\
n=8914\end{array}$ & $\begin{array}{l}\text { First Nations } \\
\text { people outside } \\
\text { First Nations } \\
\text { community } \\
n=14098\end{array}$ & $\begin{array}{c}\text { Other people } \\
n=1364222\end{array}$ \\
\hline \multicolumn{5}{|l|}{ Sex } \\
\hline Female & $12324(53.6)$ & 4649 (52.2) & 7675 (54.4) & $655137(48.0)$ \\
\hline Male & $10689(46.4)$ & $4265(47.8)$ & $6423(45.6)$ & 709085 (52.0) \\
\hline \multicolumn{5}{|l|}{ Age, yr } \\
\hline$\leq 19$ & $289(1.3)$ & $110(1.2)$ & $179(1.3)$ & $11558(0.8)$ \\
\hline $20-34$ & $1615(7.0)$ & $622(7.0)$ & $993(7.0)$ & $42554(3.1)$ \\
\hline $35-49$ & $5655(24.6)$ & $2229(25.0)$ & 3426 (24.3) & 190115 (13.9) \\
\hline $50-64$ & $9239(40.1)$ & $3543(39.7)$ & $5695(40.4)$ & 472041 (34.6) \\
\hline $65-74$ & 4108 (17.9) & 1597 (17.9) & $2511(17.8)$ & $337383(24.7)$ \\
\hline$\geq 75$ & 2107 (9.2) & $813(9.1)$ & $1294(9.2)$ & 310571 (22.8) \\
\hline \multicolumn{5}{|l|}{ Rurality† } \\
\hline Urban & $6278(27.3)$ & $97(1.1)$ & $6181(43.8)$ & 989738 (72.5) \\
\hline Suburban & 4588 (19.9) & $1192(13.4)$ & $3395(24.1)$ & $262088(19.2)$ \\
\hline Rural & 3865 (16.8) & 1149 (12.9) & 2716 (19.3) & $103251(7.6)$ \\
\hline Remote/missing & $8282(36.0)$ & $6476(72.6)$ & $1806(12.8)$ & $9145(0.7)$ \\
\hline $\begin{array}{l}{ }^{*} \text { For } 1 \text { person } i \\
\text { First Nations } \mathrm{c} \\
\text { †Determined } \mathrm{w}\end{array}$ & $\begin{array}{l}50-64 \text { yr age group, s } \\
\text { e of a First Nations co } \\
\text { ex of Ontario. }{ }^{26}\end{array}$ & $\begin{array}{l}\text { n location of residence } \\
\text { ty. Data for that person }\end{array}$ & $\begin{array}{l}\text { lld not be determ } \\
\text { luded in column }\end{array}$ & $\begin{array}{l}\text { whether he lived in a } \\
\text { not in column } 3 \text { or } 4\end{array}$ \\
\hline
\end{tabular}

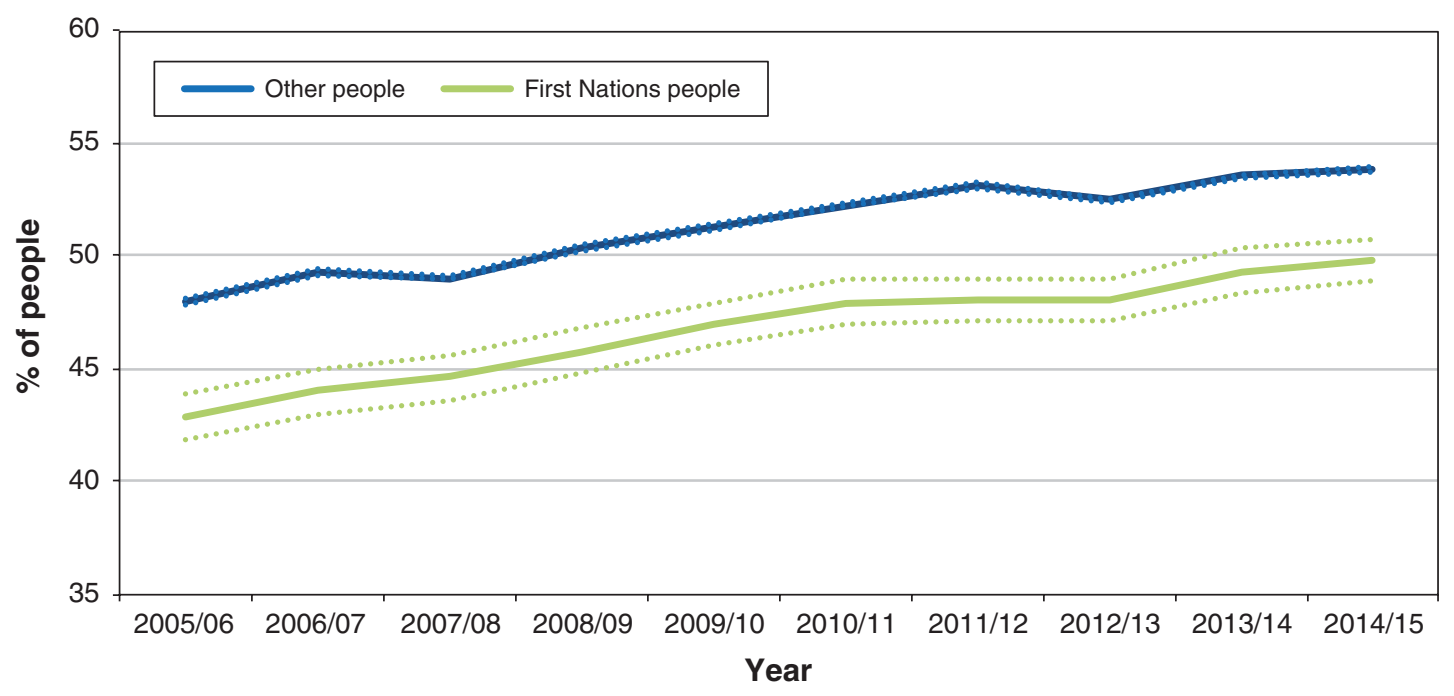

Figure 1: Proportion of First Nations people and other people in Ontario with diabetes who received an eye examination, 2005/06-2014/15 (because Ontario Health Insurance Plan funding of eye examinations changed in 2004, the baseline year was set at 2005/06 to provide data consistency). Dashed lines represent 95\% confidence intervals. 
to 244227 other people (17.9\%). Females accounted for $53.6 \%$ of First Nations people and $48.0 \%$ of other people.

Between 2005/06 and 2014/15, there was suboptimal use of eye examinations among both First Nations people and other people, with about half the population receiving an eye examination within the previous year and two-thirds receiving an eye examination in the previous 2 years (Figure 1; Appendix 1, Supplemental Figure S1). For example, 49.8\% (95\% confidence interval [CI] 48.9\%$50.7 \%$ ) of First Nations people and $53.8 \%$ (95\% CI $53.7 \%-54.0 \%$ ) of other people received an eye examination in 2014/15. Furthermore, First Nations people were less likely than other people to receive an eye examination (Figure 1; Appendix 1, Supplemental Figure S1). The proportion of First Nations people who received an eye examination during the previous year increased from $42.9 \%$ to 49.8\% between 2005/06 and 2014/15, mirroring a similar increase among other people.

Eye examination rates were similar for First Nations people regardless of whether they lived in or outside a First Nations community (Appendix 1, Supplemental Figure S2). Among both First Nations people and other people, younger people were less likely to undergo eye examinations than their older counterparts (Appendix 1, Supplemental Figure S3). Up through the age of 80 years, the proportion of people who received eye examinations increased with increasing age. Beyond 80 years of age, the proportion decreased significantly in both population groups.
First Nations people were more likely than other people to require treatment for advanced diabetic retinopathy, particularly in later study years (Figure 2). There were no significant differences in rates of diabetic retinopathy treatment in First Nations people stratified by place of residence (living in v. outside a First Nations community) (Appendix 1, Supplemental Figure S4). The differences in the proportion requiring therapy for diabetic retinopathy between First Nations people and other people were greatest among younger people (Figure 3).

In the analysis of time from diabetes diagnosis to first diabetic retinopathy treatment, the rate of progression to severe diabetic retinopathy requiring therapy was about $20 \%$ higher among First Nations people than among other people (hazard ratio 1.19, 95\% CI 1.02-1.38) (Figure 4). Overall, about $5 \%$ of First Nations people with diabetes required therapy for diabetic retinopathy within 10 years of diagnosis.

\section{Interpretation}

As part of a comprehensive, population-based study on diabetes and its consequences in the First Nations population of Ontario, we compared trends in eye examination frequency (a measure of diabetic retinopathy prevention) in 2005/06-2014/15 and diabetic retinopathy treatment rates (a measure of eye-related diabetes complications) in 1995/96-2014/15 between First Nations people and other people. We found that preventive eye examination access

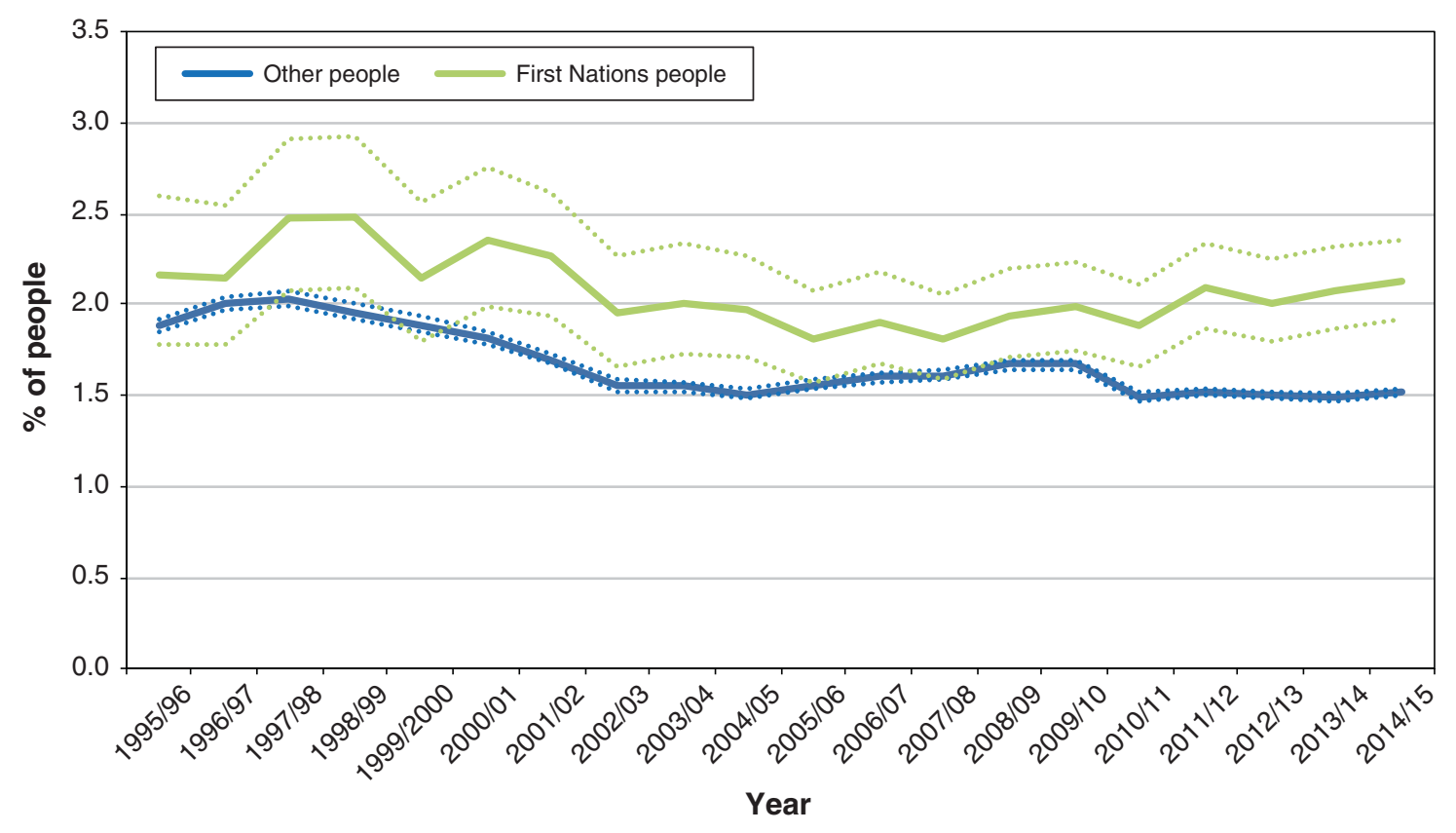

Figure 2: Age- and sex-adjusted proportion of First Nations people and other people who received any treatment for diabetic retinopathy, 1995/96-2014/15. Dashed lines represent 95\% confidence intervals. 


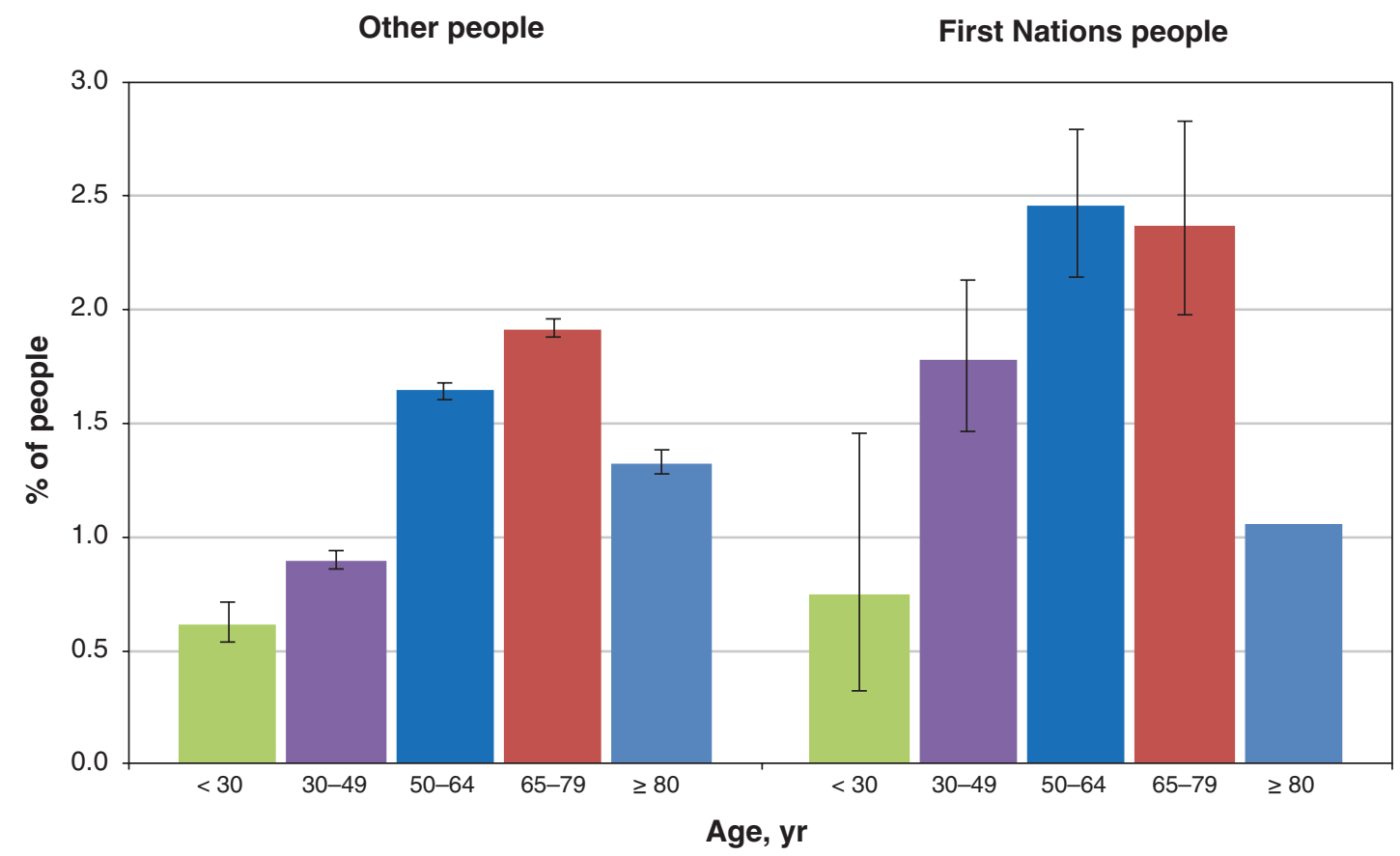

Figure 3: Proportion of First Nations people and other people who received therapy for diabetic retinopathy, by age group, 2014/15. Error bars represent $95 \%$ confidence intervals.

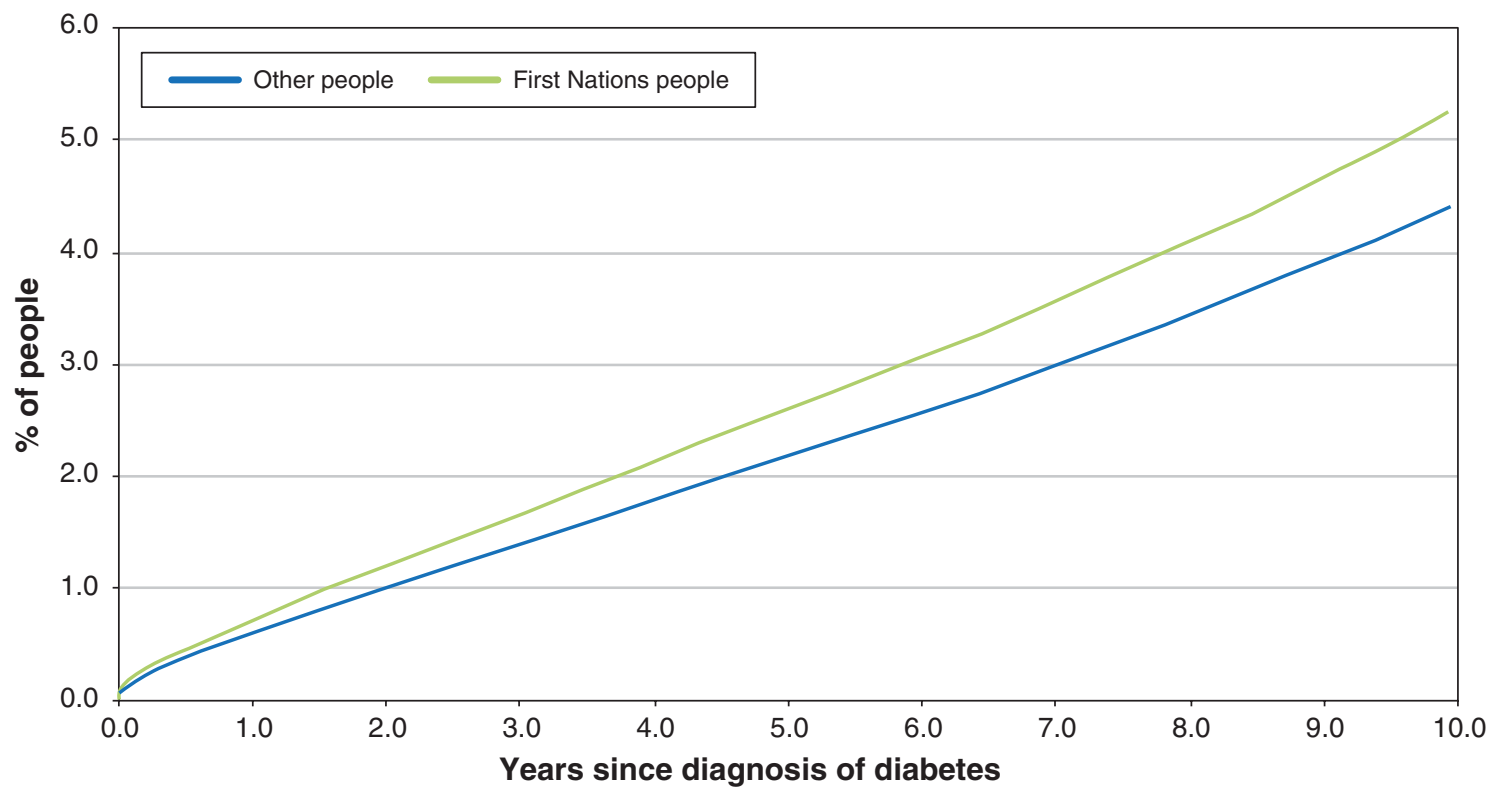

Figure 4: Age- and sex-adjusted proportion of First Nations people and other people who underwent treatment for diabetic retinopathy (intravitreal injection procedure, laser photocoagulation or vitrectomy), 1995/96-2014/15, by time since diabetes diagnosis. 
and uptake were lower than recommended among all Ontarians and were worse among First Nations people.

A Canadian guideline suggests maximum intervals between eye examinations for people without retinopathy of $1-2$ years and much more frequent examinations once retinopathy develops. ${ }^{12}$ Even when the screening interval was set at the upper limit of guideline recommendations, about one-third of people with diabetes in both population groups did not meet the recommendation.

We also found that First Nations people were more likely than other people in Ontario to require interventions for advanced stages of diabetic retinopathy and that this gap widened in the later years of the study period. Moreover, First Nations people progressed to advanced stages of diabetic retinopathy at a faster rate than other people in Ontario.

Our finding of lower-than-expected eye examination rates is consistent with other First Nations population studies ${ }^{28,29}$ and other population-based surveys. ${ }^{12,30,31}$ Our finding that First Nations people developed advanced stages of diabetic retinopathy requiring interventional therapy at a higher rate than other people also parallels findings from previous reports. ${ }^{1,5,29,32-34}$ For example, previous research using survey methodology showed low rates of eye examinations among First Nations people in British Columbia, with about 33\% receiving annual examinations. ${ }^{28}$ Medicare data showed similar rates of eye examinations among people with diabetes in the United States, reaching just $44.7 \%$ in 2014/15..$^{35}$ Although Indigenous people were not evaluated specifically, racial and ethnic backgrounds were shown to affect eye examination rates. ${ }^{35}$

The development of diabetic retinopathy can imply inadequate prevention measures, such as infrequent eye screening or inadequate control of glucose, blood pressure and lipids. Other work by our group shows that glycemic control is significantly worse in First Nations people with diabetes than in other people with diabetes in Ontario regardless of location of residence or rurality, whereas lipid control is better in First Nations people. ${ }^{36}$ Previous studies have shown that programs to support tight control of blood glucose levels and other risk factors such as blood pressure and lipid profile could reduce progression of diabetic retinopathy among First Nations people. ${ }^{33,37}$ Achieving these improvements among those most at risk, however, has proven to be complex and challenging. ${ }^{33}$

\section{Limitations}

There are several limitations to this study, including a number that are detailed in the associated methodology paper. ${ }^{18}$ First Nations people who were not registered with the federal government or were members of a First Nation that was not recognized by the Government of Canada would have been classified as other Ontarians. The Ontario Diabetes Database is limited to people who have been diagnosed with diabetes and does not include those who may have the disease but have not been diagnosed. In addition, the Ontario Diabetes Database does not distinguish between type 1 and type 2 diabetes; however, most people in both study groups had type 2 diabetes. We assumed that visits to care providers for an eye examination would include examination of the retina to evaluate the presence of diabetic retinopathy; however, it is not possible to confirm from the data whether a full examination was actually provided. However, given the importance of diabetic retinopathy, it is likely that eye examinations for people with diabetes did in fact include screening for diabetic retinopathy as indicated.

Quantification of eye care services was based on fee-forservice claims captured in the public health insurance program and did not include examinations reimbursed solely from private insurance. Although all eye examinations for people with diabetes in Ontario are covered by the public health insurance program, we cannot exclude the possibility that some visits were charged directly to patients or their private insurers and hence not captured. In addition, some people in northwestern Ontario may have received care in Manitoba and would not have been captured. This would affect only a small proportion of people and would be unlikely to affect our overall conclusions.

Potential barriers to care such as travel, missed work, caregiving demands and cultural barriers were not evaluated directly in our study, ${ }^{2,12}$ and socioeconomic status was not evaluated in our analyses.

Some of the interventions identified as outcomes may not have been treatments for diabetes-specific eye disease; however, this would not be expected to differ between the 2 study groups. Late diagnosis of diabetes could result in the appearance of more rapid progression of diabetic retinopathy, as patients may have had progressive diabetes-related disease before the date identified as the onset of diabetes.

Finally, evolution over time in the distribution of race and ethnicity in the Ontario population may have affected our findings, as these variables influence diabetes outcome rates. ${ }^{38}$

\section{Conclusion}

Eye examination rates were suboptimal among people with diabetes in Ontario, particularly First Nations people. First Nations people were more likely than other people to require treatment for advanced diabetic retinopathy, particularly in later study years, and First Nations people developed severe diabetic retinopathy at a faster rate than other people. Further analysis is needed to uncover factors that could contribute to our understanding of suboptimal screening rates in both population cohorts, including the availability of health care providers, the use of telemedicine, financial barriers and clinical factors. Additional study is also needed to understand both the increased risk of requiring treatment for advanced diabetic retinopathy and the accelerated rate of diabetic retinopathy progression in First Nations people.

\section{References}

1. Harris SB, Tompkins JW, TeHiwi B. Call to action: a new path for improving diabetes care for Indigenous peoples, a global review. Diabetes Res Clin Pract 2017;123:120-33.

2. Diabetes Canada Clinical Practice Guidelines Expert Committee; Crowshoe L, Dannenbaum D, Green M, et al. Type 2 diabetes and Indigenous peoples. Can 7 Diabetes 2018;42(Suppl 1):S296-306.

3. Pelletier C, Dai S, Roberts KC, et al. Report summary. Diabetes in Canada: facts and figures from a public health perspective. Chronic Dis Inj Can 2012;33:53-4.

4. Booth GL, Hux JE, Fang J, et al. Time trends and geographic disparities in acute complications of diabetes in Ontario, Canada. Diabetes Care 2005;28: 1045-50. 
5. Hanley AJ, Harris SB, Mamakeesick M, et al. Complications of type 2 diabetes among aboriginal Canadians: prevalence and associated risk factors. Diabetes Care 2005;28:2054-7.

6. Kempen JH, O'Colmain BJ, Leske MC, et al.; Eye Diseases Prevalence Research Group. The prevalence of diabetic retinopathy among adults in the United States. Arch Ophthalmol 2004;122:552-63.

7. CNIB Foundation; Canadian Ophthalmological Society. The cost of vision loss in Canada: summary report. Vision2020 Canada. Available: www. vision2020canada.ca/en/resources/Study/COVL\%20Summary\%20Report\% 20EN.PDF (accessed 2020 Feb. 4).

8. Diabetes in Canada. Toronto: Diabetes in Canada; 2019:1-4. Available: www. diabetes.ca/DiabetesCanadaWebsite/media/About-Diabetes/Diabetes\%20Charter/ 2019-Backgrounder-Canada.pdf (accessed 2020 Feb. 4).

9. Antonetti DA, Klein R, Gardner TW. Diabetic retinopathy. $N$ Engl 7 Med 2012;366:1227-39.

10. Cheung N, Mitchell P, Wong TY. Diabetic retinopathy. Lancet 2010;376:124-36.

11. Yau JW, Rogers SL, Kawasaki R, et al.; Meta-Analysis for Eye Disease (META-EYE) Study Group. Global prevalence and major risk factors of diabetic retinopathy. Diabetes Care 2012;35:556-64.

12. Hooper P, Boucher MC, Cruess A, et al. Canadian Ophthalmological Society evidence-based clinical practice guidelines for the management of diabetic retinopathy. Can 7 Ophthalmol 2012;47(Suppl):S1-54.

13. Diabetes among First Nations, Inuit, and Métis populations. In: Diabetes in Canada: facts and figures from a public bealth perspective. Ottawa: Public Health Agency of Canada; 2011:89-103.

14. Brown MM, Brown GC, Sharma S, et al. Utility values associated with blindness in an adult population. Br 7 Ophthalmol 2001;85:327-31.

15. The relationship of glycemic exposure $\left(\mathrm{HbA}_{1 c}\right)$ to the risk of development and progression of retinopathy in the diabetes control and complications trial. Diabetes 1995; $44: 968-83$.

16. Stratton IM, Adler AI, Neil HA, et al. Association of glycaemia with macrovascular and microvascular complications of type 2 diabetes (UKPDS 35): prospective observational study. BM7 2000;321:405-12.

17. Diabetes Canada Clinical Practice Guidelines Expert Committee; Altomare F, Kherani A, Lovshin J. Retinopathy. Can 7 Diabetes 2018;42(Suppl 1):S210-6.

18. Slater M, Green ME, Shah B, et al. First Nations people with diabetes in Ontario: methods for a longitudinal population-based cohort study. CMAf Open 2019;7:E680-8.

19. Hux JE, Ivis F, Flintoft V, et al. Diabetes in Ontario: determination of prevalence and incidence using a validated administrative data algorithm. Diabetes Care 2002;25:512-6.

20. Benchimol EI, Smeeth L, Guttmann A et al.; RECORD Working Committee. The REporting of studies Conducted using Observational Routinely-collected health Data (RECORD) statement. PLoS Med 2015;12:e1001885.

21. Campbell RJ, Bell CM, Gill SS, et al. Subspecialization in glaucoma surgery. Ophthalmology 2012;119:2270-3.

22. Campbell RJ, Bell CM, Paterson JM, et al. Stroke rates after introduction of vascular endothelial growth factor inhibitors for macular degeneration: a time series analysis. Ophthalmology 2012;119:1604-8.

23. Campbell RJ, Gill SS, Bronskill SE, et al. Adverse events with intravitreal injection of vascular endothelial growth factor inhibitors: nested case-control study. BM7 2012;345:e4203.

24. Bell CM, Hatch WV, Cernat G, et al. Surgeon volumes and selected patient outcomes in cataract surgery: a population-based analysis. Ophthalmology 2007; 114:405-10.

25. Bell CM, Hatch WV, Fischer HD, et al. Association between tamsulosin and serious ophthalmic adverse events in older men following cataract surgery. 7AMA 2009;301:1991-6.

26. Indian Act. R.S.C., 1985, c. I-5.

27. Kralj B. Measuring rurality - RIO2008_BASIC: methodology and results. Toronto: Ontario Medical Association; 2009.

28. Kaur H, Maberley D, Chang A, et al. The current status of diabetes care, diabetic retinopathy screening and eye-care in British Columbia's First Nations communities. Int 7 Circumpolar Health 2004;63:277-85.

29. Tennant MT, Greve MD, Rudnisky CJ, et al. Identification of diabetic retinopathy by stereoscopic digital imaging via teleophthalmology: a comparison to slide film. Can 7 Ophthalmol 2001;36:187-96.

30. Booth GL, Polsky JY, Gozdyra P, et al. Regional measures of diabetes burden in Ontario. Toronto: Institute for Clinical Evaluative Sciences; 2012

31. Rudnisky CJ, Tennant MTS, Johnson JA, et al. Diabetes and eye disease in Alberta. In: Johnson JA, editor. Alberta diabetes atlas 2009. Edmonton: Institute of Health Economics; 2009:153-74.

32. Ross SA, McKenna A, Mozejko S, et al. Diabetic retinopathy in native and nonnative Canadians. Exp Diabetes Res 2007;2007:76271.

33. Rudnisky CJ, Wong BK, Virani H, et al. Risk factors for progression of diabetic retinopathy in Alberta First Nations communities. Can f Ophthalmol 2017; 52(Suppl 1):S19-29.

34. Jin AJ, Martin D, Maberley D, et al. Evaluation of a mobile diabetes care telemedicine clinic serving Aboriginal communities in northern British Columbia, Canada. Int 7 Circumpolar Health 2004;63(Suppl 2):124-8.

35. Vision and Eye Health Surveillance System (VEHSS). Proportion of patients who had an eye exam in selected year. Atlanta: Centers for Disease Control and
Prevention. Available: https://nccd.cdc.gov/DDT_VEHSS/LP?LocationId=\& DataSource TypeId=CLAIMS \&DataSourceId=MEDICARE $\&$ TopicId=TUTL $\&$ CategoryId=CUTLEX\&IndicatorId=QUTLEX\&ShowFootnotes=true $\&$ Vie $\mathrm{w}=$ Chart\&CompareViewYear $=1 \&$ CompareId=RACE\&CompareId2=\&YearId =YR9\&ResponseId=REXANY\&AgeId=AGEALL\&GenderId=GALL\&RaceId $=\&$ RiskFactorId $=$ RFALL\&RiskFactorResponseId=RFTOT $\&$ DataValueTypeI $\mathrm{d}=$ CRDPREV \&MapClassifierId $=$ quantile \&MapClassifierCount $=4$ (accessed2020 Feb. 4).

36. Green M, Shah B, Slater M, et al. Monitoring, treatment and control of blood glucose and lipids in Ontario First Nations' people with diabetes: a longitudinal population-based cohort study. CMA7 2020. In press.

37. Maberley DA, King W, Cruess AF, et al. Risk factors for diabetic retinopathy in the Cree of James Bay. Ophthalmic Epidemiol 2002;9:153-67.

38. Cheng YJ, Kanaya AM, Araneta MRG, et al. Prevalence of diabetes by race and ethnicity in the United States, 2011-2016. FAMA 2019;322:2389-98.

Affiliations: Department of Ophthalmology (Campbell, Doliszny), Queen's University and Kingston Health Sciences Centre; ICES Queen's (Campbell, Khan, Frymire, Walker, Green), Kingston, Ont.; Chiefs of Ontario (Sutherland), Toronto, Ont.; Department of Ophthalmology (Hooper), Western University and St. Joseph's Hospital, London, Ont.; Department of Family Medicine (Slater, Green) and Health Services and Policy Research Institute (Frymire), Queen's University, Kingston, Ont.; ICES Central (Shah); Department of Medicine (Shah), University of Toronto and Sunnybrook Health Sciences Centre, Toronto, Ont.; School of Rural and Northern Health (Walker), Laurentian University, Sudbury, Ont.

Contributors: Robert Campbell, Roseanne Sutherland, Shahriar Khan, Morgan Slater, Eliot Frymire, Baiju Shah, Jennifer Walker and Michael Green contributed to the study conception and design. Katharine Doliszny and Philip Hooper analyzed and interpreted the data. All of the authors contributed to drafting the manuscript and revising it critically for important intellectual content, approved the final version to be published and agreed to be accountable for all aspects of the work.

Funding: This study was funded by an IMPACT Award from the Ontario SPOR SUPPORT Unit, which is supported by the Canadian Institutes of Health Research and the Province of Ontario; the Brian Hennan Chair held by Michael Green; and the David Barsky Chair held by Robert Campbell. This study was also supported by ICES, which is funded by an annual grant from the Ontario Ministry of Health and Long-Term Care.

Data sharing: The data set from this study is held securely in coded form at ICES. Although data-sharing agreements prohibit ICES from making the data set publicly available, access may be granted to those who meet prespecified criteria for confidential access. The full data set creation plan and underlying analytic code are available from the authors on request, with the understanding that the programs may rely on coding templates or macros that are unique to ICES.

Acknowledgements: The authors' partner from the early design, implementation and final dissemination of the project was the Chiefs of Ontario. Their many member contributions were key to the success and quality over the 5 years of this project. Members of the project Patient Advisory Committee provided insightful and thoughtful input for this project. Their advice made a substantial contribution in shaping both the work and this report. The authors acknowledge the First Nations people with diabetes who shared their personal stories related to the study findings.

Disclaimer: This study was supported by ICES, which is funded by an annual grant from the Ontario Ministry of Health and Long-Term Care (MOHLTC). Parts of this material are based on data and information compiled and provided by the Ontario MOHLTC and the Canadian Institute for Health Information. The sponsors of this study had no role in the design and conduct of the study; collection, management, analysis and interpretation of the data; preparation, review and approval of the manuscript; and the decision to submit for publication. The analyses, conclusions, opinions and statements expressed herein are solely those of the authors and do not reflect those of the funding or data sources; no endorsement is intended or should be inferred.

Supplemental information: For reviewer comments and the original submission of this manuscript, please see www.cmajopen.ca/content/8/2/ E282/suppl/DC1. 